$\left[\begin{array}{lcr}\text { Jpn. J. Toxicol. Environ. Health } \\ \text { 衛. } & \text { 生 } & \text { 化 } \\ 42(4) & 312-318 & \text { 学 } \\ 496)\end{array}\right]$

\title{
Microbial Degradation of Chlorhexidine by Clinical Isolates
}

\author{
Masaru Uyeda, Taeko Shiozaki, Takako Enokida, Keita Watanabe, \\ Kaori Komiya, Kazumi Yokomizo and Keitarou Suzuki \\ Faculty of Pharmaceutical Sciences, Kumamoto University, 5-1 Oe-Honmachi, \\ Kumamoto 862, Japan
}

(Received February 7, 1996)

\begin{abstract}
Chlorhexidine degradation by clinical isolates such as Pseudomonas aeruginosa, Pseudomonas cepacia, Alcaligenes faecalis, Alcaligenes xylosoxidans, Serratia marcescens and Pseudomonas sp. strain No. A-3 (as a control organism) was investigated after enrichment with chlorhexidine.

By this enrichment, P. aeruginosa (Nos.1-3), A. faecalis, A.xylosoxidans (No.2) and S. marcescens IFO 3046 smoothly acquired resistance to a high concentration of chlorhexidine.

Among them, only S. marcescens IFO 3046 showed the same degradation pattern as the control organism, which degraded chlorhexidine via a modified degradation pathway. The other strains were thought to have a different resistance system from that of Pseudomonas sp. strain No. A-3 and S. marcescens IFO 3046.
\end{abstract}

Key words__ chlorhexidine ; microbial degradation ; clinical isolates

\section{Introduction}

In our laboratories, some bacteria which are able to degrade chlorhexidine $(\mathrm{CH})$ or are resistant to it were isolated from activated sludge about ten years ago. Pseudomonas sp. strain No. A-3 (Ps. A-3) among these bacteria was able to degrade and utilize $\mathrm{CH}$ as a sole nitrogen source for its growth. Purification of $\mathrm{CH}$ degradatives has revealed that $\mathrm{CH}$ was degraded via two pathways (one is a modified degradation pathway and another is a direct degradation pathway) by this strain (Fig. 1).1)

Recently, it has been reported that many microorganisms are resistant to antibiotics ${ }^{2)}$ or disinfectants. ${ }^{3)}$ Therefore, we investigated whether or not clinical isolates could degrade CH. At first, all clinical isolates and S. mar cescens IFO 3046 were enriched with $\mathrm{CH}$ to acquire $\mathrm{CH}$ resistance. The $\mathrm{CH}$ resistant strains thus obtained were examined regarding $\mathrm{CH}$ degradation. The degradation pathway of these clinical isolates was compared to that of Ps. A-3. CHDI-B (see Fig. 1) is an indicator compound in the modified degradation pathway by PS. A-3. In this study, we examined exclusively the formation of CHDI$\mathrm{B}$ by these clinical isolates.

\section{Materials and Methods}

Disinfectant - Chlorhexidine gluconate (20\% solution) was purchased from Sumitomo Chemical Industries, Ltd. and was used without further purification.

Bacterial Strains —Ps. A-3, Pseudomonas aeruginosa (3 strains), Pseudomonas cepacia (2 strains), Alcaligenes faecalis, Alcaligenes xylosoxidans (2 strains) and Serratia marcescens (2 strains : one is obtained from IFO) were used in this study. All strains except Ps. A-3 and $S$. marcescens IFO 3046 were supplied by Kumamoto University Hospital.

\section{Determination of MIC and CH Enrichment}

Minimum inhibitory concentrations (MIC) of $\mathrm{CH}$ against each strain were determined as follows: One milliliter volumes of a two-fold strength of brain heart infusion bouillon (BHIB, Nissui Co., Ltd.) and two-fold serial dilutions of 


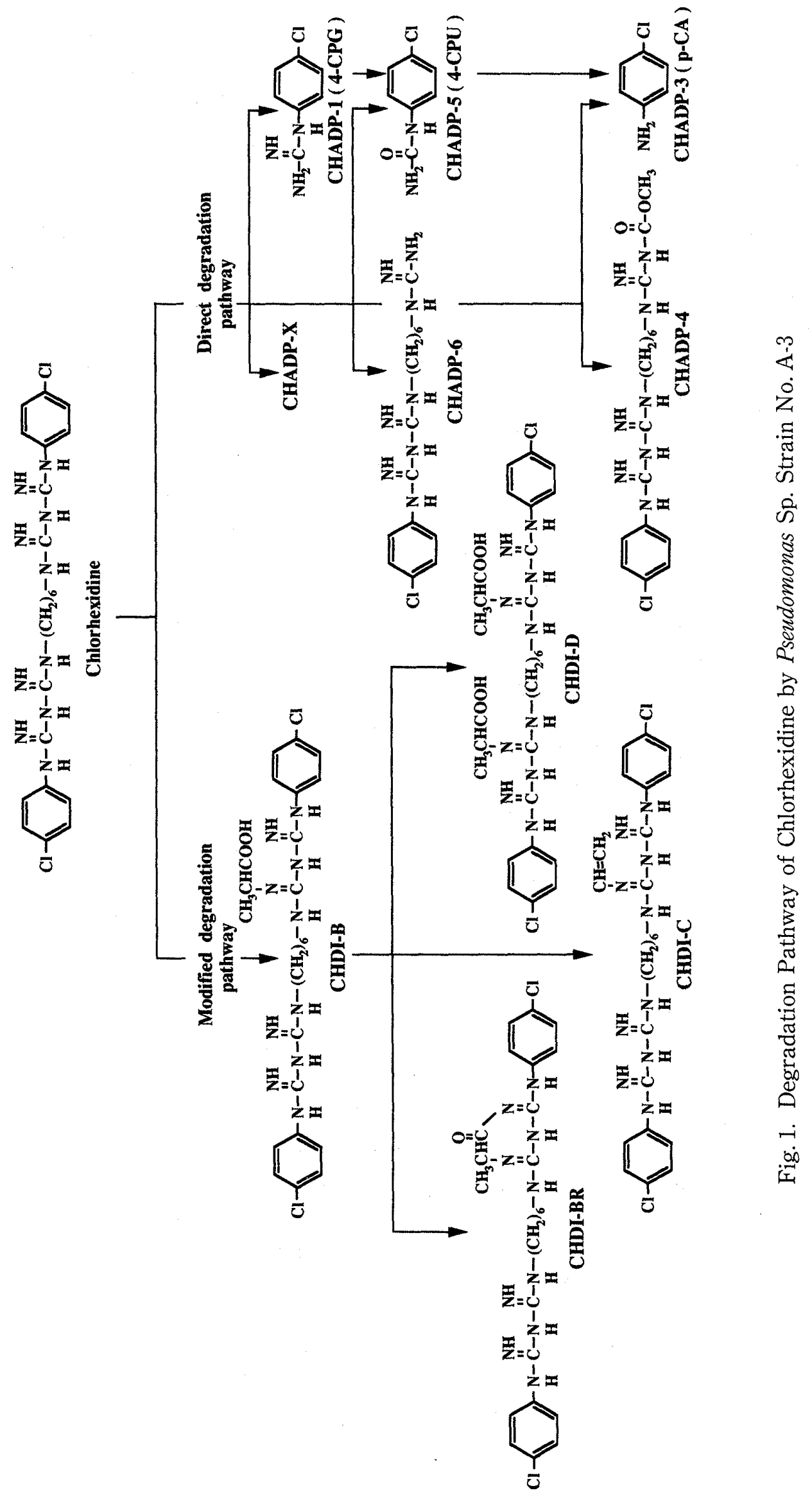


$\mathrm{CH}$ concentrations were inoculated with $5 \mu 1$ of a cell suspension (equivalent to 3 loopfuls $/ 2 \mathrm{ml}$ ) of the strains, and the MIC was determined after incubation for $24 \mathrm{~h}$ at $37^{\circ} \mathrm{C}$. The $\mathrm{CH}$ solution of more than $125 \mu \mathrm{g} / \mathrm{ml}$ made a precipitate with BHIB, so bacterial growth could not be recog. nized clearly. In this case, 2 loopfuls of each turbid culture were transferred to $\mathrm{CH}$-free $\mathrm{BHIB}$ and incubated for $24 \mathrm{~h}$ at $37^{\circ} \mathrm{C}$.

A $\mathrm{CH}$ enrichment culture of each organism was carried out to acquire $\mathrm{CH}$ resistance. Two loopfuls of the culture containing the highest concentration of $\mathrm{CH}$ in which cellular growth was observed were transferred into a medium containing higher concentrations of $\mathrm{CH},{ }^{4}$ and the culture was incubated for 1 or $2 \mathrm{~d}$ at $37^{\circ} \mathrm{C}$. This cultivation was repeatedly carried out to generate $\mathrm{CH}$ resistance.

Culture Conditions and Preparation of Intact Cells — For preparation of the intact cells of PS. A-3 for the microbial degradation of $\mathrm{CH}$, the strain was cultured in a nitrogen-limited growth medium $(30 \mathrm{ml})$ containing $\mathrm{K}$-phosphate buffer ( $6 \mathrm{~mm}, \mathrm{pH} 7.5)$, glucose $(1 \mathrm{mg} / \mathrm{ml})$, a modified Pridham and Gottlieb trace salt solution $\left(\mathrm{FeSO}_{4} \cdot \mathrm{H}_{2} \mathrm{O}\right.$ is $0.005 \mathrm{mg} / \mathrm{ml}$ and $\mathrm{CuSO}_{4} \cdot 5 \mathrm{H}_{2} \mathrm{O}$, $\mathrm{ZnSO}_{4} \cdot 7 \mathrm{H}_{2} \mathrm{O}, \mathrm{MnSO}_{4} \cdot 5 \mathrm{H}_{2} \mathrm{O}$ and $\mathrm{CaCl}_{2}$ are 0.0005 $\mathrm{mg} / \mathrm{ml}$, respectively), and chlorhexidine $(0.1 \mathrm{mg} /$ $\mathrm{ml}$ ) as a nitrogen source at $28^{\circ} \mathrm{C}$ on a rotary shaker $(180 \mathrm{rpm})$. After cultivation for $3 \mathrm{~d}$, the cells were harvested by centrifugation (12000 $\mathrm{rpm}, 10 \mathrm{~min})$ at $5^{\circ} \mathrm{C}$ and washed with sterilized water. The cells thus obtained were employed as intact cells of Ps. A-3 in the incubation mixture for CHDI-B formation. The number of intact cells in the cell suspension was determined by colony counting on a bouillon agar plate. The intact cells of each clinical isolate were prepared by almost the same method as Ps. A-3.

Incubation Mixture for CHDI-B and CHDIBR Formation _ The intact cells were resuspended with distilled water to give an optical density of 0.2 at $660 \mathrm{~nm}$. The incubation mixture $(30 \mathrm{ml})$ containing the intact cells, K-phosphate buffer (10 mM, pH 7.5), $\mathrm{CuSO}_{4}(0.001 \mathrm{~mm}), \mathrm{NAD}^{+}$ $(0.2 \mathrm{~mm})$, pyruvate $(0.5 \mathrm{mg} / \mathrm{ml})$, glucose $(10 \mathrm{mg} /$ $\mathrm{ml})$, BHIB powder $(1 \mathrm{mg} / \mathrm{ml})$ and $\mathrm{CH}(100 \mu \mathrm{g} /$ $\mathrm{ml}$ ) was incubated at $37^{\circ} \mathrm{C}$ in a $100 \mathrm{ml}$-Erlenmeyer flask for a desired length of time. After incubation, the reaction mixture was adjusted to $\mathrm{pH} 3$ with $\mathrm{HCl}$. Five milliliters of this acidic solution was passed through a Celite column (bed volume: $0.75 \mathrm{ml}$ ) and concentrations of $\mathrm{CH}, \mathrm{CHDI}-\mathrm{B}$ and CHDI-BR in the eluate were measured by HPLC. The incubation mixture was determined by the remarkable stimulation of CHDI-B and CHDI-BR formation when pyruvate, $\mathrm{NAD}^{+}$and $\mathrm{Cu}^{2+}$ ion were added to the incubation mixture.

Measurement of $\mathrm{CH}$, CHDI-B and CHDIBR _ _ HPLC was done using a jacked stainless steel analytical column $(250 \times 4 \mathrm{~mm}$ i.d. $)$ packed with LiChroCARTLi-Chrosorb RP-select B (7 $\mu \mathrm{m})$. The mobile phase was $\mathrm{CH}_{3} \mathrm{OH}-\mathrm{H}_{2} \mathrm{O} \quad(7: 3$, $\mathrm{v} / \mathrm{v}, \mathrm{pH} 3.7$ ) containing $5 \mathrm{~mm}$ 1-heptanesulfonic acid. The concentrations of $\mathrm{CH}, \mathrm{CHDI}-\mathrm{B}$ and CHDI-BR were measured by HPLC on an apparatus equipped with a UV detector set at $254 \mathrm{~nm}$.) The injection volume for this study was $5 \mu \mathrm{l}$ of sample solution. The quantification of each compound was achieved by the use of a calibration curve for each.

\section{Results and Discussion}

\section{Acquisition of $\mathrm{CH}$ Resistance}

Table I shows the process of acquisition of $\mathrm{CH}$ resistance by $P$. aeruginosa No. 3 . The initial MIC of $\mathrm{CH}$ against $P$. aeruginosa No. 3 was determined to be $7.8 \mu \mathrm{g} / \mathrm{ml}$. The bacteria which were cultured in $3.9 \mu \mathrm{g} / \mathrm{ml}$ of $\mathrm{CH}$ were transferred into media containing the higher concentrations of $\mathrm{CH}$. The strain became resistant to $\mathrm{CH}$, which acquired resistance to $1000 \mu \mathrm{g} / \mathrm{ml}$ as MIC after $5 \mathrm{~d}$. To attain $\mathrm{CH}$ resistant strains, the same method was used for the other strains.

Table II indicates the acquisition degree of $\mathrm{CH}$ resistance by various strains. The acquisition degree of $\mathrm{CH}$ resistance was calculated by dividing the MIC against a resistant strain by that against prototroph. For example, the $\mathrm{CH}$ resistant $S$. marcescens IFO 3046 in Table II had acquired 1282-fold higher 
TABle I. Process of Acquisition of $\mathrm{CH}$ Resistance by $P$. aeruginosa No.3

\begin{tabular}{cccccc}
\hline \hline $\mathrm{MIC}^{a)}$ & \multicolumn{5}{c}{ Incubation time $(\mathrm{d})^{b)}$} \\
\cline { 2 - 6 }$(\mu \mathrm{g} / \mathrm{ml})$ & 0 & 1 & 2 & 3 & 5 \\
\hline 10000 & - & - & - & - & - \\
5000 & - & - & - & - & - \\
2500 & - & - & - & - & - \\
1250 & - & - & - & - & - \\
1000 & - & - & - & - & - \\
500 & - & - & - & - & + \\
250 & - & - & - & + & \\
125 & - & - & + & & \\
62.5 & - & + & & & \\
31.3 & - & + & & & \\
15.6 & - & + & & & \\
7.8 & - & + & & & \\
3.9 & + & & & & \\
2.0 & + & & & & \\
0 & + & & &
\end{tabular}

a) Higher $\mathrm{CH}$ concn. above $125 \mu \mathrm{g} / \mathrm{ml}$ made precipitate with BHIB, so each culture was transferred to $\mathrm{CH}$-free BHIB and MIC was determined after incubation for $24 \mathrm{~h}$ (see text). b) Time to acquire $\mathrm{CH}$ resistance. + , growth observed; -, growth not observed.

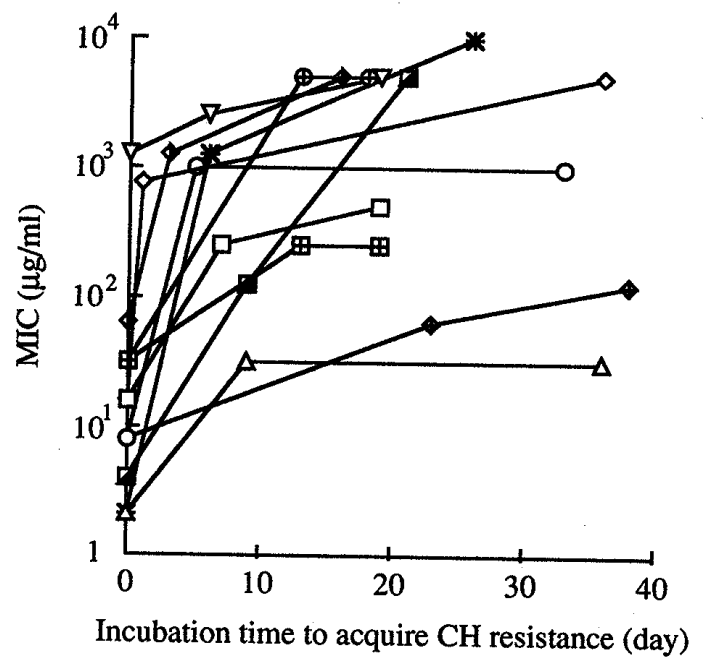

Fig. 2. Diagram to Show Acquisition of $\mathrm{CH}$ Resistance

$-\square-$, P. aeruginosa No. $1 ;-\diamond-, P$. aeruginosa No. 2 ; - - , P. aeruginosa No. $3 ;-\triangle-, P$. cepacia No. 1 ; 一田一, P. cepacia No. $2 ;-\uparrow-$, A. xylosoxidans No. 1; $-\oplus-$, A. xylosoxidans No. $2 ;-\nabla-$, S. marcescens No. $1 ;-\square-$, S. marcescens IFO $3046 ;-\triangleleft-$, A. faecalis ; -*-, Ps. A-3.

TABLE II. Acquisition Degree of $\mathrm{CH}$ Resistance by Clinical Isolates

\begin{tabular}{|c|c|c|c|c|c|c|c|c|c|c|c|}
\hline \multirow{2}{*}{ Strain } & \multicolumn{3}{|c|}{$P$. aeruginosa } & \multicolumn{2}{|c|}{ P. cepacia } & \multirow{2}{*}{ A faecalis } & \multicolumn{2}{|c|}{ A. xylosoxidans } & \multicolumn{2}{|c|}{ S. marcescens } & \multirow{2}{*}{ PS. A-3 } \\
\hline & No.1 & No.2 & No.3 & No.1 & No.2 & & No.1 & No.2 & No.1 & IFO 3046 & \\
\hline $\begin{array}{l}\text { MIC against prototroph } \\
(\mu \mathrm{g} / \mathrm{ml})\end{array}$ & 15.6 & 15.6 & 7.8 & 2.0 & 31.3 & 62.5 & 7.8 & 31.3 & 1250 & 3.9 & 2.0 \\
\hline $\begin{array}{l}\text { MIC against resistant } \\
\text { strain }(\mu \mathrm{g} / \mathrm{ml})\end{array}$ & 500 & 5000 & 1000 & 31.3 & 250 & 5000 & 125 & 5000 & 5000 & 5000 & 10000 \\
\hline $\begin{array}{l}\text { Acquisition degree } \\
\text { of } \mathrm{CH} \text { resistance }{ }^{a)}\end{array}$ & 32 & 320 & 128 & 16 & 8 & 80 & 16 & 160 & 4 & 1282 & 5000 \\
\hline
\end{tabular}

resistance than the prototroph strain. The acquisition degree of $\mathrm{CH}$ resistance of $A$. xylosoxidans and $S$. marcescens were particularly different from each other. The acquisition degree of $\mathrm{CH}$ resistance of A. xylosoxidans No. 2 (value 160) was higher than that of the strain No. 1 (value 16). The difference was caused by MIC values against the resistant strains. On the other hand, the acquisition degree of $S$. marcescens No. 1 was very low because the prototroph itself already showed very high MIC (the clinical isolate had already become resistant to $\mathrm{CH}$ ). These results were in good accordance with the report that the susceptibility of Gramnegative bacteria to commonly used disinfectants varied strain to strain as indicated by Gotou et. al. ${ }^{6)}$ The time courses of various isolates in acquiring $\mathrm{CH}$ resistance are shown in Fig. 2. Some isolates such as $A$. faecalis, $P$. aeruginosa Nos. 2 and 3 and $S$. marcescens (also Ps. A-3) acquired resistance to about $1000 \mu \mathrm{g} / \mathrm{ml}$ as MIC in only a few $\mathrm{d}$.

\section{Comparison of Various Strains on CH De- gradability}

The strains that acquired higher $\mathrm{CH}$ 

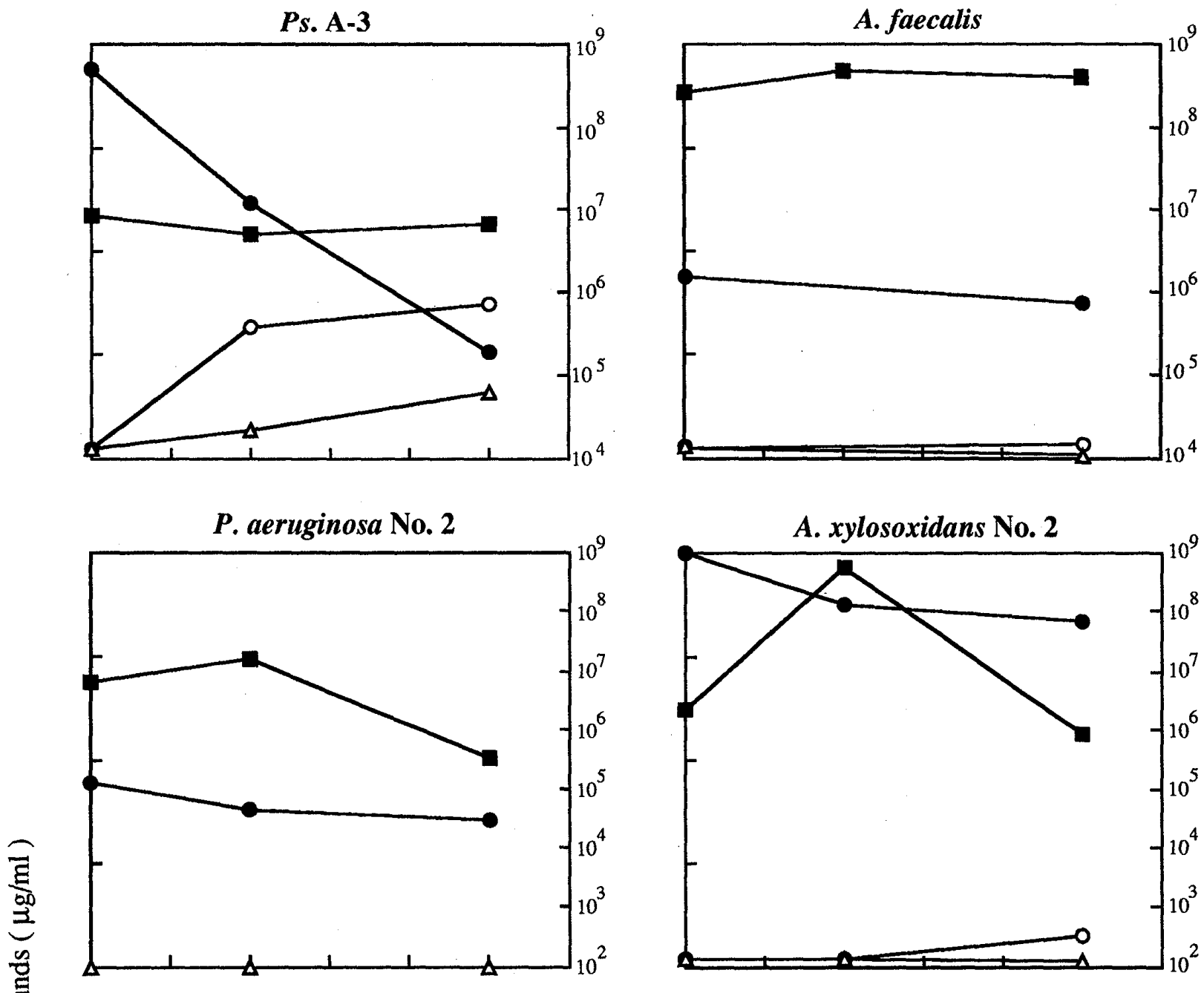

A. xylosoxidans No. 2

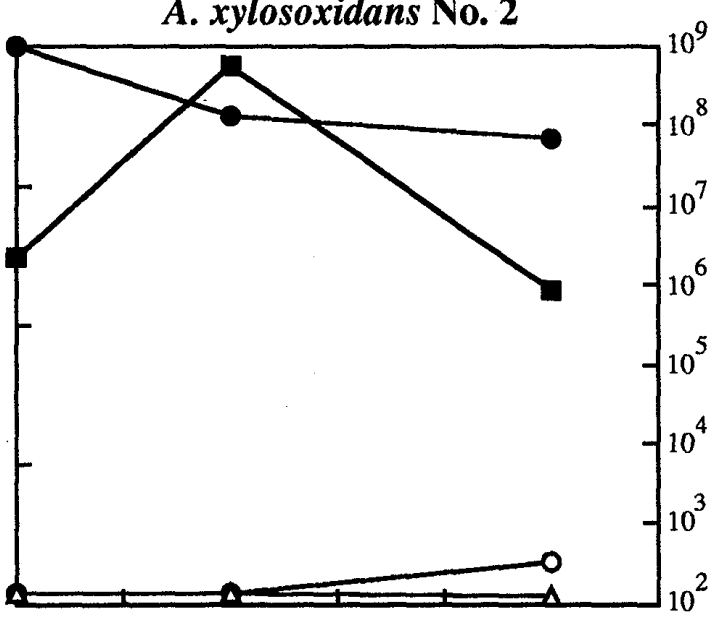

P. cepacia No. 2

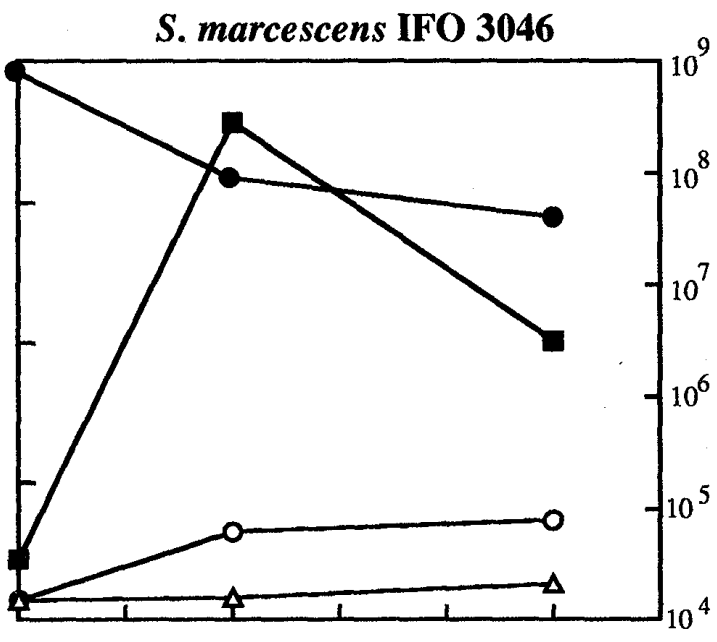

Incubation time (day)

Fig. 3. Time Course of $\mathrm{CH}$ Degradation by Various Clinical Isolates

$0.1 \%$ BHIB was supplemented to each incubation mixture except Ps. A-3. $-\mathrm{O}-\mathrm{CH} ;-\triangle-$,

CHDI-B ; - - , CHDI-B +CHDI-BR ; - - cells $/ \mathrm{ml}$. 
resistance, $P$. aeruginosa No. 2, $P$. cepacia No. 2, A. faecalis, A.xylosoxidans No. 2 and $S$. marcescens IFO 3046 were examined for $\mathrm{CH}$ degradability in the next step. PS. A-3 was used as a positive control (Fig. 3).

Ps. A-3 was observed to form $\mathrm{CH}$ degradative products with a decrease in $\mathrm{CH}$. Among these strains, S. marcescens IFO 3046 appeared to form $\mathrm{CH}$ modified degradative products such as CHDI-B and CHDI-BR. As shown in Fig. 4, the HPLC chart of $\mathrm{CH}$ degradatives by $S$. marcescens showed almost the same pattern as that by PS. A-3 under the same condition. Therefore, we inferred that the strain had the same $\mathrm{CH}$ modified degradative pathway as Ps. A-3. On the other hand, the other strains formed a trace amount or no $\mathrm{CH}$ modified degradative products, although BHIB or peptone was supplemented for the incubation mixture to improve their growth (Fig. 3). These strains were thought to have a different resistance system than that of Ps. A-3 as a CH-degradation pathway. S. marcescens No. 1 had already become resistant to $\mathrm{CH}$ in the hospital, therefore, the clinical isolate might be alive under an envi- ronment where the higher concentration of $\mathrm{CH}$ exists. A. faecalis, $P$. aeruginosa No.2, $A$. xylosoxidans, S. marcescens IFO 3046 and Ps. A-3 acquired $\mathrm{CH}$-resistance quickly and the degree of resistance of these isolates was very high (MIC above $5000 \mu \mathrm{g} / \mathrm{ml}$ ). If they settled in the hospital, they would become $\mathrm{CH}$ resistant strains and may cause an infection in the hospital.

The resistance mechanism to $\mathrm{CH}$ by gram-negative bacteria has been investigated by many researchers. That mechanism was not yet fully understood. However, as one of the mechanisms, we reported previously that the lipid content in the cells of $\mathrm{CH}$-resistant $S$. marcescens were higher than those of the prototroph cells; therefore, the difference in the lipid content was thought to be significant in relation to structural differences of the cell envelope of $\mathrm{CH}$ resistant strains. ${ }^{4}$ In this paper, we reported that $S$. marcescens also has a $\mathrm{CH}$ modified degradative pathway similar to that of Ps. A-3. S. marcescens has two mechanisms for $\mathrm{CH}$-resistance, therefore, the strain may acquire resistance quickly, highly and stably.

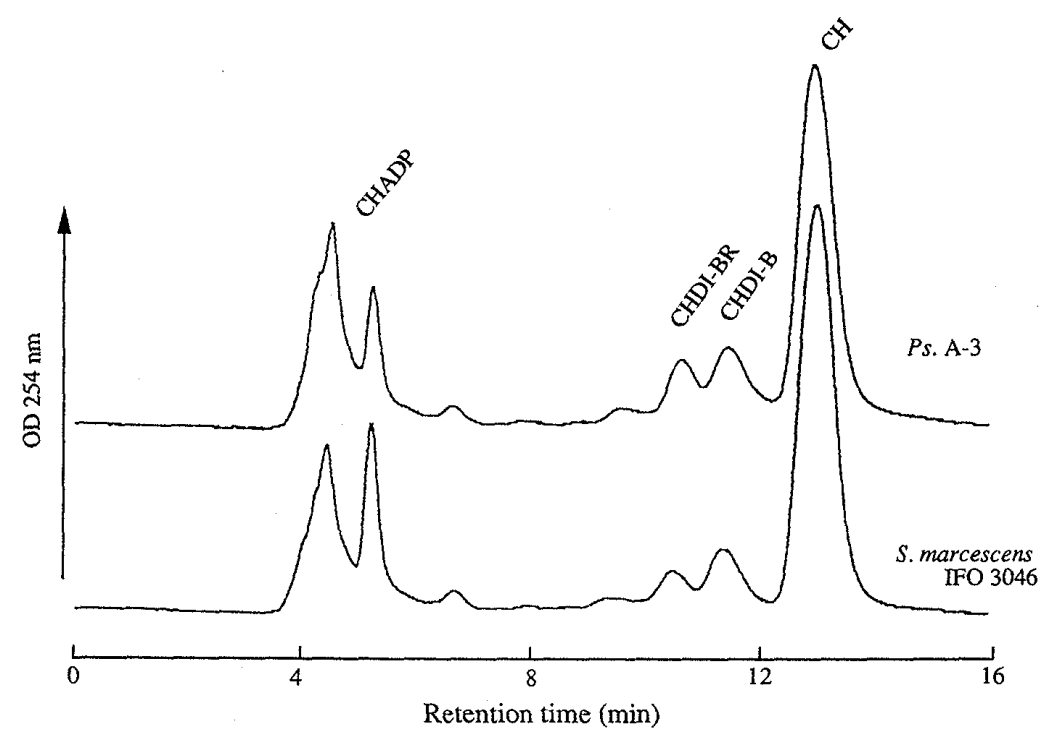

Fig. 4. Comparison of HPLC Chromatograms

Column, LiChrosorb RP-select B $(7 \mu \mathrm{m}, 250 \times 4 \mathrm{~mm}$ i.d.) ; flow rate, $0.8 \mathrm{ml} / \mathrm{min}$; detection, OD $254 \mathrm{~nm}$; mobile phase, $\mathrm{CH}_{3} \mathrm{OH}-\mathrm{H}_{2} \mathrm{O}(7: 3, \mathrm{v} / \mathrm{v}, \mathrm{pH} 3.7)$ containing $5 \mathrm{~mm}$ 1-heptanesulfonic acid. 
Acknowledgments We thank Prof. Nobu-

University for the supply of clinical isolates.

hisa Yamane of the Medical School of Kumamoto

\section{References}

1) Y. Kido, H. Kodama, F. Uraki, M. Uyeda, M. Tsuruoka and M. Shibata, Eiseikagaku, 34, 10 (1988) ; idem, ibid., 34, 319 (1988) ; H. Kodama, T. Hashimoto, M. Tsuruoka, Y. Kido, M. Uyeda and M. Shibata, ibid., 34, 408 (1988) ; Y. Kido, H. Kodama, F. Uraki, M. Uyeda, M. Tsuruoka and M. Shibata, ibid., 34, 97 (1988) ; Y. Kido, H. Kodama, Y. Isohama, M. Uyeda and M. Shibata, ibid., 36, 139 (1990) ; M. Uyeda, T. Shiosaki, K. Yokomizo, K. Suzuki, F. Uraki, T. Tanaka and Y. Kido, Jpn. J. Toxicol. Environ. Health, 42, 121 (1996).

2) B.R. Lyon and R. Skurray, Genetic Basis Microbiol. Rev., 51, 88 (1987) ; H. Yasuda, Y. Ajiki, T.Koga, H. Kawada and T. Yokota, Antimicrob. Agents Chemother., 37, 1749 (1993); K. Hiramatsu, Bioscience and Industry, 52, 11 (1994).

3) H.N. Prince, W.S. Nonemaker, R.C. Norgard and D.L. Prince, J. Pharmaceut. Sci., 67, 1629 (1978) ; G. Nicoletti, V. Boghossian, F. Gurevitch, R. Borland and P. Morgenroth, J. Hosp. Infect., 23, 87 (1993). T. Shiraishi and Y. Nakagawa, Postgrad. Med. J., 69, (Suppl. 3), 70 (1993); P.A. Gandhi, A.D. Sawant, L.A. Wilson and D.G. Ahearn, Appl. Environ. Microbiol., 59, 183 (1993).

4) M. Uyeda, M. Shibata, T. Hitoshi and A. Miura, Chemotherapy, 29, 733 (1981) ; M. Uyeda, M. Sakata, M. Shibata and T. Hitoshi, ibid., 30, 286 (1982).

5) C.E. Huston, P. Wainwright and M. Cooke, J. Chromatogr., 237, 457 (1982).

6) S. Gotou, Y. Kaneko and K. Kawasaki, Rinsho Byori, 25, 684 (1977). 